Article

\title{
Experimental and Numerical Determination of the Local Fiber Volume Content of Unidirectional Non-Crimp Fabrics with Forming Effects
}

\author{
Siegfried Galkin ${ }^{1}$, Eckart Kunze ${ }^{2}$, , Luise Kärger ${ }^{1, *}$, Robert Böhm ${ }^{2}$ and Maik Gude ${ }^{2}$ \\ 1 Karlsruhe Institute of Technology (KIT), Institute of Vehicle System Technology, Lightweight Technology \\ (LBT), Rintheimer Querallee 2, D-76131 Karlsruhe, Germany; siegfried.galkin@kit.edu \\ 2 Institute of Lightweight Engineering and Polymer Technology, Technical University Dresden, \\ D-01307 Dresden, Germany; eckart.kunze@tu-dresden.de (E.K.); robert.boehm1@tu-dresden.de (R.B.); \\ maik.gude@tu-dresden.de (M.G.) \\ * Correspondence: luise.kaerger@kit.edu; Tel.: +49-721-608-45386
}

Received: 18 January 2019; Accepted: 10 February 2019; Published: 14 February 2019

\begin{abstract}
Detailed knowledge of the local fiber orientation and the local fiber volume content within composite parts provides an opportunity to predict the structural behavior more reliably. Utilizing forming simulation methods of dry or pre-impregnated fabrics allows for predicting the local fiber orientation. Additionally, during the forming process, so-called draping effects like waviness, gapping or shear-induced transverse compression change the local fiber volume content. To reproduce and investigate such draping effects, different manufacturing tools have been developed in this work. The tools are used to create fabric samples with pre-defined deformation states, representing the different draping effects. The samples are evaluated regarding the resulting fiber volume content. The experimental results are compared with the predictions of an analytical solution and of a numerical solution based on draping simulation results. Furthermore, the interaction of the draping effects at arbitrary strain states is discussed regarding the resulting fiber volume content.
\end{abstract}

Keywords: draping effects; fiber deformation; process simulation; preforming; fiber volume content; waviness; gapping; shearing

\section{Introduction}

The structural performance of continuous fiber-reinforced polymer (CoFRP) parts strongly depends on fiber orientation and fiber volume content (FVC). For complex geometries, the forming process, also called a draping process, mainly defines these two parameters. When preforming the two-dimensional textile fabrics like stitched unidirectional non-crimp fabrics (UD-NCF) onto a three-dimensionally curved tool, deformation of the fabric in the form of shearing, waviness or fiber gapping may occur. These deformations result in a reorientation of the fibers and a deviation from the target FVC. These process-dependent effects are called draping effects. From a structural simulation point of view, an accurate knowledge of the draping effects is necessary to predict the structural behavior of CoFRP parts more precisely. Since the fiber orientation and FVC of each ply can only be determined using nondestructive testing (NDT) methods with a high amount of effort [1,2], a draping simulation can more easily provide the necessary local information. Therefore, a suitable and reliable draping simulation is needed, which provides local information about present roving waviness, gapping or roving compression due to shear. This information can be mapped to the structural simulation by means of continuous virtual process chains (a.k.a. computer-aided engineering (CAE) chains) to consider draping effects [3-5]. 
It is well known that the FVC has an influence on the stiffness and strength of CoFRPs [6-9]. For varying FVC of non-undulated fibers, several homogenization methods are available to compute the effective stiffness, e.g., VOIGT and REUSS provide boundaries for the moduli in different directions. The influence of waviness on the structural behavior in connection with FVC has been investigated in several publications [10-15]. If the amplitude to wavelength ratio is increased, the effective moduli of the composite decrease in the fiber direction and increase in the shear and transverse direction. The rate of stiffness increase or decrease depends on the FVC [12]. Besides stiffness, the failure phenomenology and strength also depend on the waviness [16-19]. If waviness occurs in the fabric, the local FVC changes because of an increased local fiber mass. In addition, the effective stiffness of a unit cell with a present waviness and a specific FVC can be calculated [20]. However, the waviness-dependent varying local FVC is neither considered nor easily available.

Since the FVC influences the permeability of fabrics, many publications have determined and considered the local FVC to predict mold filling more reliably by molding simulation [21-26]. Based on draping simulation for woven [21,27] and stitched bi-directional fabrics [21], the resulting FVC can be transferred to the mold filling simulation. The resulting FVC was determined by the shear angle resulting from draping the fabric. However, the deformation mechanisms of UD-NCF fabrics, as used in this investigation, are quite different compared to woven or stitched bi-directional fabrics. UD-NCF membrane deformation behavior is characterized by combined large shear and transverse strain, and thus cannot be captured by kinematic models or simplified material models that assume pure shear deformation behavior. Therefore, the resulting FVC of UD-NCF needs to be estimated from the total deformation of the fabric.

Recent investigations have shown the capabilities of draping simulation with accurate material modeling approaches capturing the distinct material behavior under membrane or bending loads [28-30]. Such models provide the necessary information about local fiber orientation and local deformations that influence the FVC and roving waviness. In this paper, a new approach is presented which allows determining the local FVC of UD-NCF based on draping simulation results. To validate simulation results and FVC predictions, experimental tests are conducted. Here, the FVC is determined by the areal weight of the fabric for a specific thickness of the laminate. The goal of this work is to determine and analyze the FVC for different draping effects. The FVC of a fabric increases by shearing the fibers or inducing waviness and decreases by separating the fibers. For that purpose, fiber volume contents between $48 \%$ to $60 \%$ are adjusted either by shearing, starting from $48 \%$, or by creating gaps, starting from $60 \%$. Furthermore, waves with an amplitude to wavelength ratio between 0 and 0.2 are manufactured to evaluate the increase of the FVC. Typical amplitude to wavelength ratios of automotive parts have been identified in the range between 0 and 0.1 . In doubly curved areas of geometrically complex parts, this ratio can increase significantly. For all investigated configurations, different analytical, experimental and numerical methods are presented to determine the global distribution of the FVC for the deformed state of the fabric. Additionally, the interaction of different draping effects is analyzed and the impact on the FVC is discussed. The proposed methods can be used to link draping and structural simulation by the transfer of locally varying fiber volume contents. This provides a further step to a closed CAE chain for a more reliable prediction of the structural behavior of CoFRP parts.

\section{Preform Manufacturing}

\subsection{Materials}

A unidirectional carbon fiber non-crimp fabric (UD-NCF) of the type PX35 from Zoltek (Nyergesujfalu, Hungary) was used for preform manufacturing. The PX35 fabric is characterized by a pre-applied powder binder and $5 \mathrm{~mm}$ wide rovings $(50 \mathrm{~K})$. The target areal weight is $330 \mathrm{~g} / \mathrm{m}^{2}$. Adjacent rovings of this fabric are fixed in place by connecting neighboring loops with a polyester stitching yarn. The tricot loop of the warp knitted yarn forms a characteristic zigzag pattern on one 
side of the fabric and thus gives the fabric a high shearing resistance. On the other side of the fabric, an additional 34 dtex glass roving is added perpendicular to the UD reinforcement which gives this side a checked pattern. The powder binder is an epoxy based adhesive (Huntsman XB 3366, Basel, Switzerland). It sticks to the surface of the fabric in the form of small droplets on the zigzag side only. Binder technology is used for the assembly of preforms as an alternative to sewing [31]. In this case, it is used to freeze the draping effects after deformation. The binder is a thermoset with thermoplastic properties: it can be melted several times, which is useful in preform preparation. According to the manufacturer, the binder has a melting point of $150^{\circ} \mathrm{C}$ and should not be subjected to $200{ }^{\circ} \mathrm{C}$ longer than $2 \mathrm{~min}$ in circulating air and to $190^{\circ} \mathrm{C}$ longer than $25 \mathrm{~s}$ in direct contact. The fixation by the binder is only effective for temperatures below the binder melting point. At high press forces, the fixation by the binder depends on the amount of binder used per square meter, on the activation parameters and tool temperatures during press forming. If the binder is activated at high temperatures for too long, the binder migrates into the fibers and the fixation effect is lost.

\subsection{Wavy Patterns}

In the literature, several approaches for producing out-of-plane waviness are suggested [32,33]. For that purpose, thick laminates with 70 to 150 ply laminates are manufactured. To receive in-plane waves, these thick laminates are cut into slices [17,32]. DAVIDSON [34] tested specimens with one half wave in thick laminates that were manufactured by inserting pre-cured resin blocks into the laminate. The manufacturing process of thick laminates is very time-consuming and difficult in terms of air entrapment. For that reason, thin laminates with in-plane waves are preferred for manufacturing of wavy specimens. BRÖCKEL [33] describes several methods to induce in-plane wavy deformations, among others a sliding and a swivel mechanism. The first mechanism deforms the fibers by moving sliders perpendicular to the fiber direction while the fibers are not actively compressed in longitudinal direction in which they contract. The second mechanism uses swivel arms, which form parallelograms and actively move the fibers in perpendicular and longitudinal direction. It was found that the swivel mechanism is more suited, since it induces fewer irregularities in the deformed fabrics [33]. However, one disadvantage of the swivel mechanism is that a specific mechanism can only be used to produce a single amplitude $A$ for a given wavelength $\lambda$, since both parameters change during the swivel motion.

Preliminary investigations at Karlsruhe Institute of Technology (KIT) Institute of Vehicle System Technology showed the occurrence of fiber waviness with a wavelength of $10 \mathrm{~mm}$ to $20 \mathrm{~mm}$ and a deflection of $2 \mathrm{~mm}$ to $5 \mathrm{~mm}$. For the proposed study, a modified slider mechanism was designed. The slider mechanism is more suited for small wavelengths. In contrast, the moving parts of the more complex swivel mechanism limit the smallest adjustable wavelength and amplitude. Furthermore, for every single $A / \lambda$-ratio, one swivel mechanism is necessary, whereas any $A / \lambda$-ratio can be adjusted for a given wavelength with one sliding mechanism. To reproduce draping effects for mechanical testing, a specimen with a sinusoidal wave with a defined wavelength of $\lambda=20 \mathrm{~mm}$ and a varying amplitude $A=0 \mathrm{~mm}$ to $4 \mathrm{~mm}$ were manufactured. The deformed section has a length of $5 \lambda$. Figure 1 shows the principle of the tool.

The sliding mechanism consists of 20 ledges, which are $5 \mathrm{~mm}$ wide and feature a needle every $5 \mathrm{~mm}$. Galvanized fine wire staples with a diameter of $0.7 \mathrm{~mm}$, glued into an aluminum strip, are used for the needles. The fabric is applied on top of the needles and pushed downwards so that the needles penetrate the fabric. Then, the ledges are pushed simultaneously into opposite directions by master plates which define the amplitude of the wave. The two-step preforming process consists of a first forming and activation step for each individual ply of the stack, and a second stacking and activation step to form the whole six-ply laminate. In the first step, the wavy pattern is fixed by activating the binder with a hot air gun when the fabric is still attached to the needle strips. This process step takes place without compression. After careful removal from the tool, the waves remain in the preform. In the second step, all plies are accurately stacked upon each other and joined in a membrane press by activating the binder for the second time. The forces in the membrane press are created by a vacuum 
and do not exceed a pressure of $0.09 \mathrm{MPa}$. Movements of the fibers within the flat preform can, thus, be excluded.

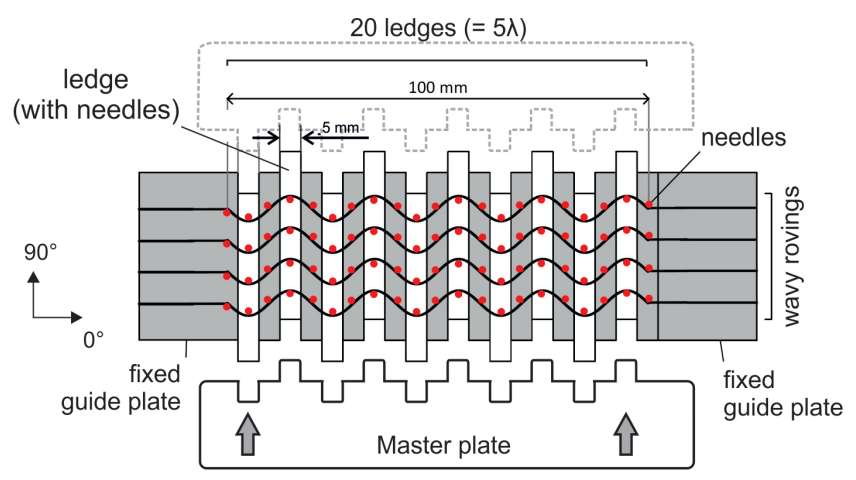

Figure 1. Sliding mechanism with ledges (needles in red) to induce sinusoidal waves into fabrics.

\subsection{Fiber Gapping}

The mechanism introduced to form waves was slightly modified to induce gaps into a fabric (Figure 2). Instead of shifting the ledges with needles in parallel, a small spacer strip is pushed in-between adjacent ledges. Thus, the fabric is elongated in a transverse direction and gaps occur between the roving bundles. The gap size is determined by the width of the spacer. Spacers of several widths are used to adjust different gap sizes. Each ply is gapped separately, since binder activation would not fix the gaps in the preformed ply. As the flexible stitching yarn only holds the rovings together, an additional fixation layer must be added to each gapped ply. An undeformed ply is attached on top of each gapped ply with spray adhesive. In this way, the rovings of the first ply stick to the fixation layer maintaining the gaps. After three stacks of a gapped and a fixation ply are manufactured, the next steps involves the assembly and activation of the complete stack in the membrane press.

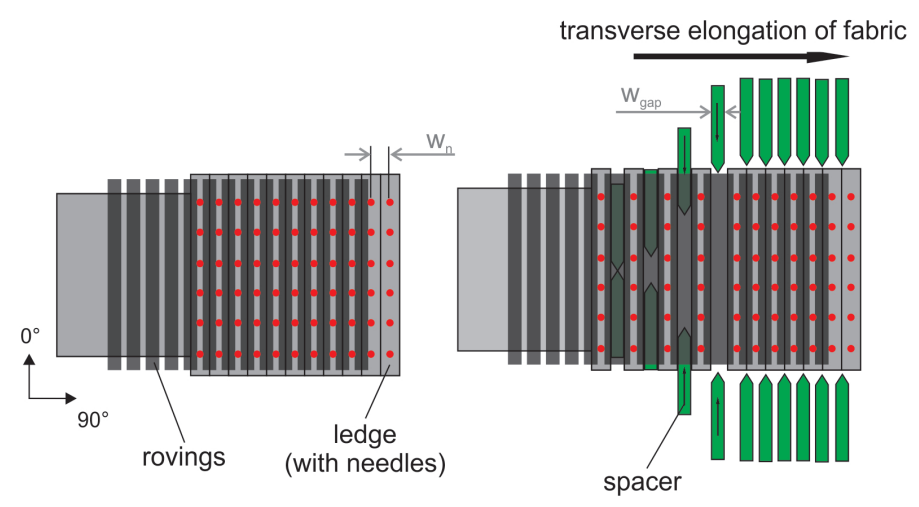

Figure 2. Sliding mechanism with needle ledges to induce gaps between the roving bundles (black—roving, grey—ledge with needles (red), dark grey—spacer ). (Left): undeformed state; (Right): spacers are inserted between the needle ledges

\subsection{Fiber Shearing}

A shear frame is used to create fiber shearing. The fabric is clamped along the edges of the parallel linked shear frame which has joints at its corners (Figure 3). All six NCF plies are deformed at once using the shear frame. After the desired angle is adjusted, the joints are fixed and the shear frame with the plies is placed in the membrane press to activate the binder. 


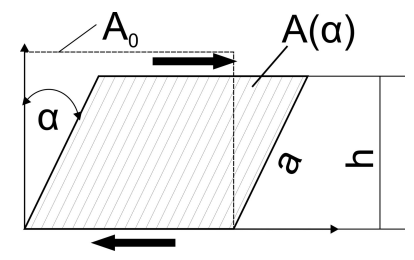

Figure 3. Shear frame mechanism inducing a pure shear strain state with shear angle $\alpha$, initial edge length $a$ and deformed height $h$.

\section{Forming Simulation}

To determine fiber volume contents for UD-NCF from draping simulation, a suitable draping simulation model is required. Such a model was developed and published by SCHIRMAIER [28,30]. The model is briefly described in the following.

\subsection{Strain Measures}

The initial undeformed configuration is defined by line segments $t_{1}^{0}$ and $t_{2}^{0}$, which both correspond to the principal directions of the material (see Figure 4). After deformation, the line segments are expressed in the current configuration by

$$
t=F \cdot t^{0}
$$

where $\boldsymbol{F}$ is the deformation gradient. Based on the current configuration, the linear but non-orthogonal strains $\varepsilon_{1}$ and $\varepsilon_{2}$ are given by

$$
\varepsilon_{i}=\frac{\left|t_{i}\right|}{\left|t_{i}^{0}\right|}-1=\sqrt{\sum_{j} F_{i j}^{2}}-1, \quad i, j=1,2,
$$

where $F_{i j}$ are components of the deformation gradient. The shear strain (in radians) is calculated directly from the deformed line segments $t_{1}$ and $t_{2}$ (cf. Figure 4)

$$
\gamma_{12}=\gamma_{1}+\gamma_{2}=\frac{\pi}{2}-\psi_{12}=\frac{\pi}{2}-\arccos \left(\frac{t_{1} \cdot t_{2}}{\left|t_{1}\right| \cdot\left|t_{2}\right|}\right) .
$$

Additionally, a further linear strain component perpendicular to the fiber direction $\varepsilon_{\perp}$ is introduced, which is calculated directly from the perpendicular line segment $t_{\perp}$ and its initial configuration $t_{\perp}^{0}$ (cf. Figure 4)

$$
\varepsilon_{\perp}=\frac{\left|t_{\perp}\right|}{\left|t_{\perp}^{0}\right|}-1=\frac{\left|t_{2}\right| \sin \left(\psi_{12}\right)}{\left|t_{2}^{0}\right|}-1=\sqrt{F_{12}^{2}+F_{22}^{2}} \sin \left(\psi_{12}\right)-1
$$
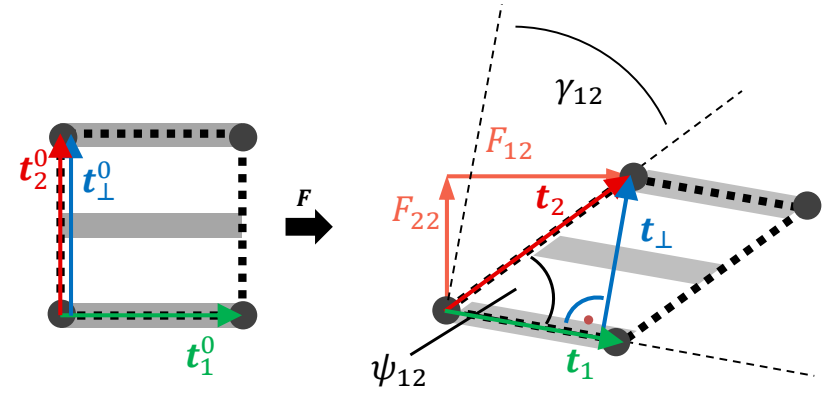

initial configuration

current configuration

Figure 4. Schematic representation of the calculation of linear strain components (according to [28]). 


\subsection{Constitutive Equations}

The model uses non-orthogonal strain measures $\varepsilon$ and a nominal stress tensor $\boldsymbol{P}^{*}$ to model non-orthogonal material behavior due to large shear deformation. Based on the non-orthogonal strain measures, the stress-strain relation can be described by an orthotropic stiffness matrix $C$

$$
\boldsymbol{P}^{*}=\left(\begin{array}{c}
P_{11}^{*} \\
P_{22}^{*} \\
P_{21}^{*}
\end{array}\right)=\left(\begin{array}{ccc}
\frac{E_{1}}{1-v_{12} v_{21}} & \frac{v_{21} E_{1}}{1-v_{12} v_{21}} & 0 \\
\frac{v_{12} E_{2}}{1-v_{12} v_{21}} & \frac{E_{2}}{1-v_{12} v_{21}} & 0 \\
0 & 0 & G_{12}
\end{array}\right)\left(\begin{array}{c}
\varepsilon_{1} \\
\varepsilon_{2} \\
\gamma_{12}
\end{array}\right)=C \boldsymbol{\varepsilon}
$$

It is assumed that the shear stress $P_{21}^{*}$ directly depends on the shear angle $\gamma_{12}$ [28,30]. In case of positive transverse strain (strain of the stitching) $\varepsilon_{2}>0$, there may still be a transverse compression perpendicular to the fibers (cf. Figure 5). This cannot be captured by the strain component $\varepsilon_{2}$ alone and, thus, the perpendicular strain component $\varepsilon_{\perp}$ is used to calculate the transverse compression stress $P_{\perp}$. To ensure a disjunction between $P_{22}^{*}$ and $P_{\perp}$ in case of compressive transverse strain $\left(\varepsilon_{2}<0\right), E_{2}$ is set to zero. On the other hand, $P_{\perp}$ equals zero for the case $\varepsilon_{\perp}>0$. Since it is assumed that the strain components $\varepsilon_{2}$ and $\gamma_{12}$ consist of an elastic and a plastic part,

$$
\begin{array}{r}
\varepsilon_{2}=\varepsilon_{2}^{e l}+\varepsilon_{2}^{p l}, \\
\gamma_{12}=\gamma_{12}^{e l}+\gamma_{12}^{p l},
\end{array}
$$

an elastic-plastic formulation is used to consider nonlinear material behavior due to shear and transverse tension [28,30]. The plastic domain applies, if the yield conditions $\Gamma_{2}$ and $\Gamma_{12}$ are satisfied according to

$$
\begin{gathered}
\Gamma_{2}=P_{22}^{*}-R_{2 \Gamma}\left(\varepsilon_{2}^{p l}, \gamma_{12}\right) \leq 0, \\
\Gamma_{12}=P_{21}^{*}-R_{12 \Gamma}\left(\gamma_{12}^{p l}\right) \leq 0,
\end{gathered}
$$

where $R_{2 \Gamma}$ and $R_{12 \Gamma}$ define the hardening curves due to tensile load of the stitching and due to shear loads.

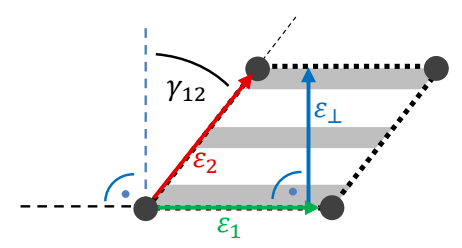

Figure 5. Distinction between transverse strain $\varepsilon_{2}$ and perpendicular strain $\varepsilon_{\perp}$.

\subsection{Model Parameter Identification}

To determine the necessary material parameters, off-axis tension (OAT) tests are performed. The test setup and evaluation was performed according to recently published experiments $[28,30,35]$. The OAT tests were performed with three different fiber orientations $\theta=\left\{30^{\circ}, 45^{\circ}, 60^{\circ}\right\}$ (cf. Figure 6). Yield curves for transverse tension and shear are determined from the test results and a best parameter fit is performed to calibrate the model. 


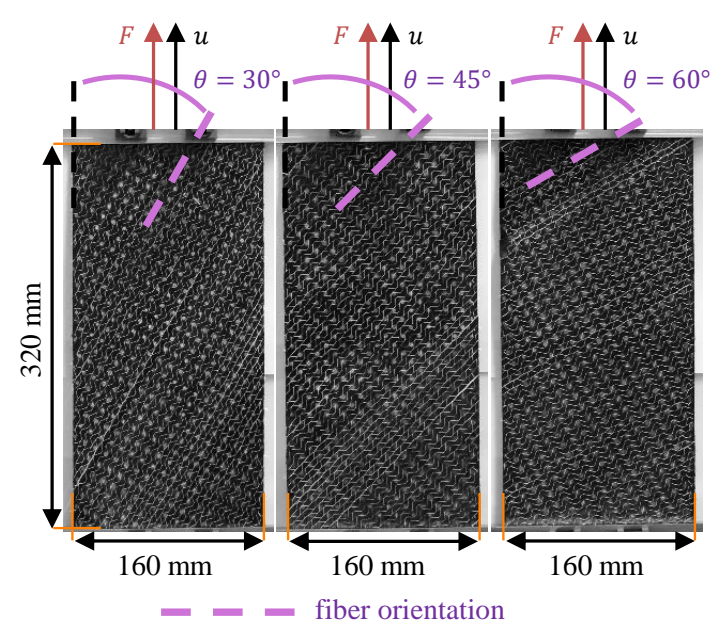

Figure 6. Definition of the fiber orientation for off-axis tension tests.

\subsection{Simulation Setup}

According to the preforming process of UD-NCF fabrics to generate waviness, gaps and transverse compression due to shear (Section 2), a simulation model is created using ABAQUS. The dimensions of the simulated fabric ply are coincident with the experimental samples. Since all plies in a preform are deformed by the same load case, the simulation model is set up for one ply only. The interaction between equally oriented plies is negligible and has no influence on the final deformation. Distinct boundary conditions are applied for each configuration. Since the needles from one ledge to another ledge have a specific distance of $w_{\mathrm{n}}=5 \mathrm{~mm}$, the displacement conditions are applied to all nodes at intervals of $5 \mathrm{~mm}$ along the fiber direction, beginning from the edge of the ply at $x=0$ (cf. Figure 7). An analytical field expression was applied to generate the configuration-specific displacements. For a wavy pattern, the relative displacement of the ledges to each other are defined by a sinusoidal displacement

$$
u_{\mathrm{y}}=A \sin \left(\frac{2 \pi}{\lambda} x\right) \text {, }
$$

where $A$ defines the amplitude, $\lambda$ the wave length and $x$ the node coordinate along the fiber direction (cf. Figure 7a). All other displacements are fixed $\left(u_{\mathrm{x}}=u_{\mathrm{z}}=0\right)$. Comparable to the wavy pattern, gapping is created by using displacement boundary conditions at each node at intervals of $5 \mathrm{~mm}$ along the fiber direction, beginning from the edge of the ply at $y=0$. The node specific displacement is defined by

$$
u_{\mathrm{y}}=\frac{w_{\mathrm{gap}}}{w_{\mathrm{n}}} y,
$$

where $w_{\text {gap }}$ defines the gap between the ledges, $w_{\mathrm{n}}$ the ledge width and $y$ the node coordinate transverse to the fiber direction (cf. Figure $7 \mathrm{~b}$ ). Similar to the wavy pattern, the displacements $u_{\mathrm{x}}$ and $u_{\mathrm{z}}$ are equal to zero. A pure shear load case is necessary to model transverse compression due to shear. The displacements are applied similar to the shear frame on the outer edges of the ply. The amount of shearing is defined by $\gamma_{12}$. Each node on the outer edges (cf. Figure $7 \mathrm{c}$ ) has an impressed displacement by analytical field expressions

$$
u_{\mathrm{x}}=y \sin \left(\gamma_{12}\right) \quad \text { and } \quad u_{\mathrm{y}}=y\left(\cos \left(\gamma_{12}\right)-1\right) .
$$

The displacement in the $z$-direction is fixed $\left(u_{z}=0\right)$. 
(a)

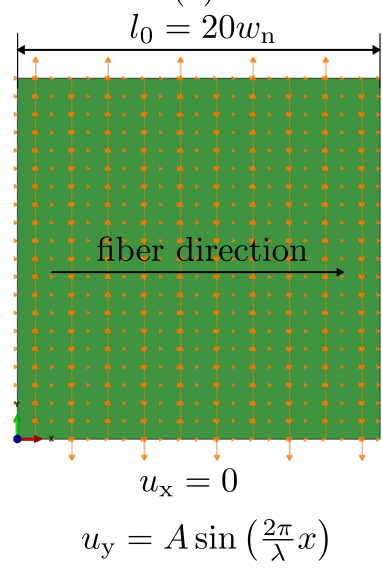

(b)

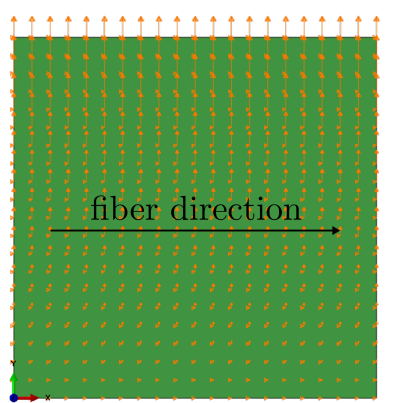

$u_{\mathrm{x}}=0$

$u_{\mathrm{y}}=\frac{w_{\text {gap }}}{w_{\mathrm{n}}} y$ (c)

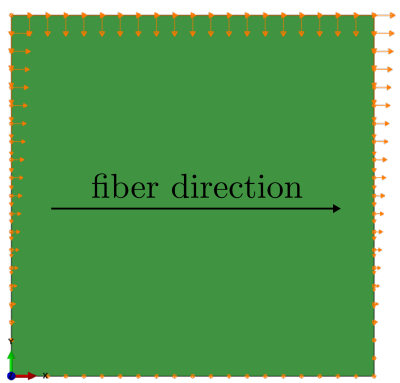

$$
\begin{gathered}
u_{\mathrm{x}}=y \sin \left(\gamma_{12}\right) \\
u_{\mathrm{y}}=y\left(\cos \left(\gamma_{12}\right)-1\right)
\end{gathered}
$$

Figure 7. Load case definition for wavy pattern (a); gapping (b); and shearing (c).

\section{Methods to Determine the Resulting Fiber Volume Content}

The FVC of a preform is determined by the volume of fibers in a defined area of the preform with a given thickness. For an undeformed fabric sample with straight fiber orientation (fiber length $l=l_{0}$ ), the FVC can be calculated by

$$
\varphi_{\mathrm{f}}=\frac{n_{\mathrm{L}}}{\rho_{\mathrm{f}} \cdot t} \cdot m_{\mathrm{A}_{0}}
$$

where $m_{\mathrm{A}_{0}}$ is the initial fabric weight per unit area, $\rho_{\mathrm{f}}$ is the density of the fibers, $t$ represents the cavity height or laminate thickness and $n_{\mathrm{L}}$ the number of fabric layers. The initial fabric weight per unit area $m_{\mathrm{A}_{0}}$ is defined by the fraction of the fabric weight $m_{\mathrm{f}_{0}}$ and the unit area $A_{0}$ :

$$
m_{\mathrm{A}_{0}}=\frac{m_{\mathrm{f}_{0}}}{A_{0}} .
$$

In the following sections, the calculation of the FVC results is shown for a specifically defined thickness of the laminate/cavity height.

\subsection{Determination of the Fiber Volume Content Based on Experiments}

Forming trials were conducted with the tools described above. The shape of the deformed fabric was fixed in place by activating the powder binder. A reference area for weighing the deformed samples was marked. The outline of the reference area was masked with adhesive tape. This method avoids fiber misalignment before cutting and ensures exact dimensions. $100 \mathrm{~mm} \times 100 \mathrm{~mm}$ samples (for wavy and gapped preforms) and $200 \mathrm{~mm} \times 200 \mathrm{~mm}$ samples (for sheared preforms) were precisely cut with a computer-controlled flatbed cutter and weighed with an analytical scale to determine the areal weight $m_{A_{i}}$ (index $i$ : $w \hat{=}$ wavy, $g \hat{=}$ gapped, $s \hat{=}$ sheared) after forming. With $m_{\mathrm{A}_{i}}$, the FVC

$$
\varphi_{\exp , i}=\frac{n_{\mathrm{L}}}{\rho_{\mathrm{f}} \cdot t} \cdot m_{\mathrm{A}_{i}}
$$

can be determined for a preform with draping effects at an arbitrary thickness. A photograph documented the amplitude and wavelength of each layer of the wavy preform. Computer tomography was applied to assess the accuracy after ply assembly to a complete preform stack. The goal of the CT scan is to check if the curves of the waves are located one upon the other. Changes in wavelength or amplitude can be checked by measuring the distance between the crests of a wave. Using CT scans, the gapping distance and fiber orientation can also be verified for gapped preforms. A phoenix $\mathrm{v}$ |tome|x L 450 cone beam X-ray system was used for specimen inspection (tube voltage: $160 \mathrm{kV}$ and current: $150 \mu \mathrm{A}$ ). The resulting voxel size is $40 \mathrm{~m} /$ vox. The experimental results will be discussed in Section 5.2. 


\subsection{Determination of the Fiber Volume Content Based on Analytical Predictions}

\subsubsection{Wavy Pattern}

To determine the FVC of a wavy fiber area with sinusoidal waves, the following assumption is applied: in a fabric with a constant area $A_{0}$ and wavy rovings, the length of a roving increases by the difference between its arc length $l_{\lambda, \mathrm{A}}$ and the unstretched length $l_{0}$. For a sinusoidal wave

$$
f(x)=A \sin \left(\frac{2 \pi}{\lambda} x\right)
$$

the arc length reads

$$
l_{\lambda, \mathrm{A}}=\int_{0}^{l_{0}} \sqrt{1+\left(\frac{\mathrm{d} f}{\mathrm{~d} x}\right)^{2}} \mathrm{~d} x=\int_{0}^{l_{0}} \sqrt{1+\left(\frac{2 \pi A}{\lambda}\right)^{2} \cos ^{2}\left(\frac{2 \pi}{\lambda} x\right)} \mathrm{d} x
$$

depending on the wave length $\lambda$ and the amplitude $A$. The new FVC $\varphi_{\mathrm{w}}(\lambda, \mathrm{A})$ can be determined by

$$
\varphi_{\mathrm{w}}(\lambda, \mathrm{A})=\frac{n_{\mathrm{L}}}{\rho_{\mathrm{f}} \cdot t} \cdot m_{\mathrm{A}_{0}} \cdot \frac{l_{\lambda, \mathrm{A}}}{l_{0}} .
$$

\subsubsection{Fiber Gapping}

To create fiber gapping, single rovings are separated by the distance $w_{\text {gap }}$ by moving the ledges with the width $w_{\mathrm{n}}$ further apart. The new FVC $\varphi_{\mathrm{g}}$ is calculated by

$$
\varphi_{\mathrm{g}}\left(w_{\text {gap }}\right)=\frac{n_{\mathrm{L}}}{\rho_{\mathrm{f}} \cdot t} \cdot m_{\mathrm{A}_{0}} \cdot \frac{w_{\mathrm{n}}}{w_{\mathrm{n}}+w_{\text {gap }}} .
$$

To avoid injection runners when gapped layers are stacked upon each other, an undeformed fixation layer is added after each gapped layer. The stack consists of equal amounts of gapped and non-gapped layers and $\varphi_{\mathrm{g} \text {,stack }}$ is the average of Equations (11) and (17):

$$
\varphi_{\mathrm{g}, \text { stack }}=\frac{\varphi_{\mathrm{f}}+\varphi_{\mathrm{g}}\left(w_{\mathrm{gap}}\right)}{2}=\frac{1}{2} \frac{n_{\mathrm{L}}}{\rho_{\mathrm{f}} \cdot t} \cdot m_{\mathrm{A}_{0}} \cdot\left(1+\frac{w_{\mathrm{n}}}{w_{\mathrm{n}}+w_{\text {gap }}}\right) .
$$

Solving Equation (18) for $w_{\text {gap }}$ gives the desired gapping distance to adjust a specific FVC in the preform:

$$
w_{\text {gap }}=\frac{2 w_{\mathrm{n}}\left(\varphi_{\mathrm{f}}-\varphi_{\mathrm{g}, \text { stack }}\right)}{2 \varphi_{\mathrm{g}, \text { stack }}-\varphi_{\mathrm{f}}}
$$

\subsubsection{Fiber Shearing}

When shearing a fabric sample with the initial surface area $A_{0}$, its mass remains constant, while the surface area decreases to $A(\alpha)$ by the shearing deformation. Corresponding to Equation (17), the FVC for a sheared fabric yields

$$
\varphi_{\mathrm{s}}(\alpha)=\frac{n_{\mathrm{L}}}{\rho_{\mathrm{f}} \cdot t} \cdot \frac{m_{\mathrm{f}_{0}}}{A(\alpha)}=\frac{n_{\mathrm{L}}}{\rho_{\mathrm{f}} \cdot t} \cdot m_{\mathrm{A}_{0}} \cdot \frac{A_{0}}{A(\alpha)} .
$$

The deformed surface area $A(\alpha)$ of the sheared fabric sample can be expressed by (cf. Figure 3)

$$
A(\alpha)=A_{0} \sin \left(90^{\circ}-\alpha\right)=a \cdot h
$$


with the shear angle $\alpha$, the height $h$ and the edge length $a$ of the sheared square fabric. Solving Equation (21) for $\alpha$ and utilizing Equation (20) gives the required shear angle

$$
\alpha=90^{\circ}-\arcsin \left(\frac{n_{\mathrm{L}} \cdot m_{\mathrm{A}_{0}}}{\rho_{\mathrm{f}} \cdot t \cdot \varphi_{\mathrm{s}}(\alpha)}\right)
$$

for a specific target FVC $\varphi_{\mathrm{S}}(\alpha)$. This approach has been applied before for woven fabrics [5,21,23-26] to predict local FVC. This approach is legitimate since the main deformation behavior of woven fabrics is a pure shear deformation.

\subsection{Determination of the Fiber Volume Content Based on Simulation}

Within the present work, the main factors for varying fiber volume contents are the variation of the area (owing to gapping or shear) at a constant fabric weight or the change of the fabric weight (wavy pattern) at a constant area. The analytical methods presented above to determine the FVC are applicable only for uniform distributions of the FVC. In a final composite part, the locally varying FVC cannot be determined by such methods. Utilizing draping simulation can provide the necessary information about the local FVC, which is important for a more realistic prediction of the structural performance.

Since the draping model uses a macroscopic approach, a change in the local fabric weight caused by roving sliding inside the stitching (as for the wavy pattern) cannot be captured directly. The imposed boundary conditions for the wavy pattern create a strain in fiber direction that is not present in real material behavior. Usually, forming simulations with a macroscopic model predicts only marginal strains in fiber direction, since the fiber is considered to be inextensible. Therefore, fiber strain resulting from modeling a wavy pattern cannot be taken into account to compute a change of the local fabric weight. The deformation of the elements is rather evaluated in a simulation post-processing step in order to subsequently determine the FVC. Considering the deformation of each element, the element area change $\Delta A$ can be determined. Finally, by assuming a constant fabric weight per element, the FVC can be calculated by extending Equation (11) to

$$
\varphi_{\mathrm{f}}=\frac{n_{\mathrm{L}}}{\rho_{\mathrm{f}} \cdot t} \cdot \frac{m_{\mathrm{A}_{0}}}{\Delta A}
$$

where $\Delta A$ defines the percentage change of the element area. A similar approach has been used for woven fabrics $[5,21,23-26]$ by utilizing the shear angle to estimate the area change. For plane deformation, the element area change can be calculated by utilization of the deformation gradient

$$
A=\operatorname{det}(\boldsymbol{F}) A_{0}=\left(F_{11} F_{22}-F_{12} F_{21}\right) A_{0}=\Delta A \cdot A_{0} .
$$

For unrestricted boundary conditions, the local FVC can be estimated by using Equations (23) and (24). For the wavy pattern (Figure 7a), the simple shear load case is induced by restricted boundary conditions. For such load case, the element area remains constant (cf. Figure 8a). Hence, the FVC due to an increase of the local fabric weight cannot be determined by the resulting element area according to Equation (24). Therefore, the perpendicular strain $\varepsilon_{\perp}$ is used to determine the perpendicular compression/elongation and, thus, the changed FVC for such special load case. For a simple shear load case, the area of a deformed square can be calculated from its edge lengths (cf. Figure $8 b$ ). If the initial edge length is defined as $l_{0}$, the deformed area yields

$$
A=\left(1+\varepsilon_{1}\right) l_{0}\left(1+\varepsilon_{\perp}\right) l_{0}=\left(1+\varepsilon_{1}\right)\left(1+\varepsilon_{\perp}\right) l_{0}^{2}=\left(1+\varepsilon_{1}\right)\left(1+\varepsilon_{\perp}\right) A_{0}=\Delta A \cdot A_{0} .
$$

Equation (25) represents an alternative to Equation (24) to determine the element area, which is only valid for simple shear caused by roving sliding, as artificially induced in this work to achieve the wavy pattern. Generally, the strain in fiber direction $\varepsilon_{1}$ is very small compared to other strain 
components. Therefore, in the case of simple shear, the strain in fiber direction is neglected and the fabric weight is distributed over a reduced area

$$
A=\left(1+\varepsilon_{\perp}\right) A_{0}=\Delta A \cdot A_{0}
$$

(a)

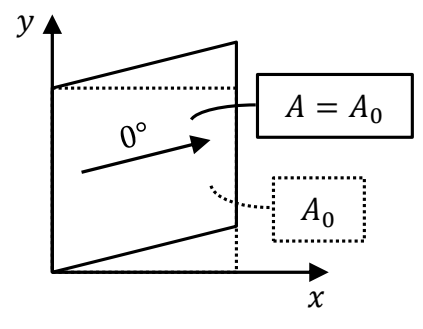

(b)

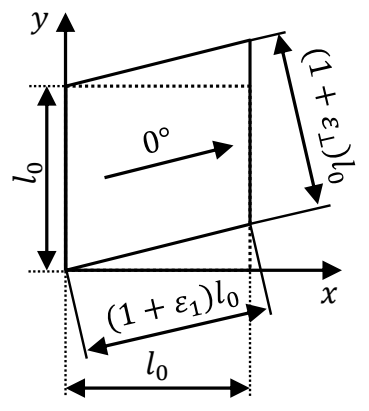

Figure 8. Simple shear deformation caused by roving sliding (e.g., for the wavy pattern) (a) and square area change due to this slip-induced deformation $(\mathbf{b})$.

\section{Results and Evaluation of the Fiber Volume Content Prediction Quality}

\subsection{Simulation Results}

Using the previously defined simulation setup, each configuration is evaluated regarding the resulting FVC. For all simulation results, the perpendicular strain $\varepsilon_{\perp}$ is unequal to zero (cf. Figure 9). Besides perpendicular strain, the fiber gapping and shearing create only one active strain component ( $\varepsilon_{2}$ for fiber gapping and $\gamma_{12}$ for shearing). On the other hand, the wavy pattern creates a simple shear load case where the shear strain $\gamma_{12}$ is unequal to zero. Additionally, large strains in fiber direction $\varepsilon_{1}$ arise. This high strain, however, does not represent the actual material behavior, but is solely caused by the applied boundary conditions to reproduce the sliding of the fibers through the yarn. Therefore, the change of the area is calculated via Equation (26) rather than (24).

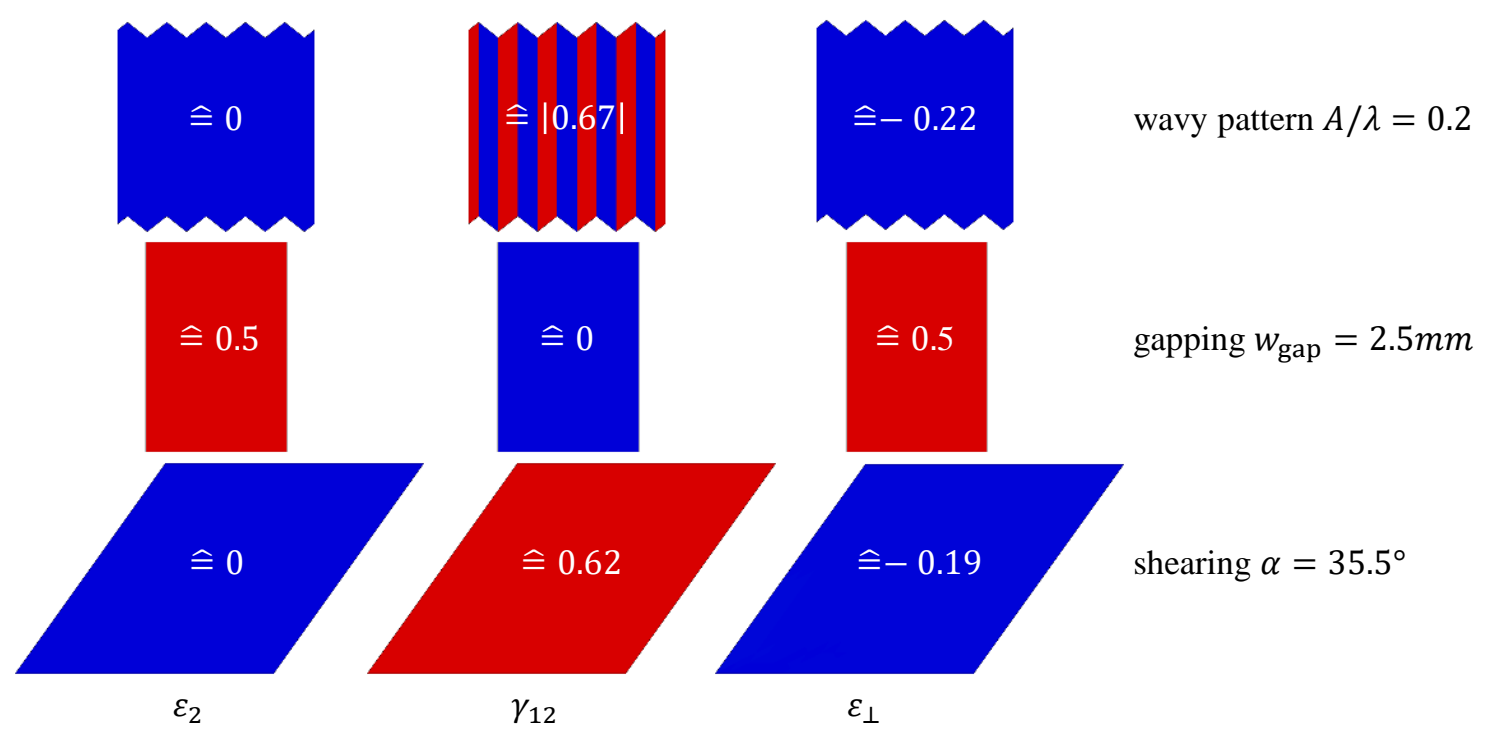

Figure 9. Strain components for selected load cases for each draping effect.

As shown in Figure 9 for uniform load cases, such as gapping and shearing, very high transverse strains $\varepsilon_{2}$ up to $50 \%$ and shear strains $\gamma_{12}$ up to 0.62 rad occur in the fabric. For a wavy pattern with an amplitude to wavelength ratio $A / \lambda$ of 0.2 , the shear strain can even raise to 0.67 rad. Additionally, 
the shear strain is alternating at the turning points, indicating a sudden change of the deformation, which can result in local gapping (see Figure 10).

Since all load cases create a uniform strain distribution (cf. Figure 9), the FVC is calculated via Equation (23) in combination with (24) or (26) for the element area change $\Delta A$. Both equations for $\Delta A$ lead to the same results for fiber gapping and shearing. In case of the wavy pattern simulation, large fiber strains $\varepsilon_{1}$ occur and, thus, only Equation (26) leads to a realistic prediction of the FVC. A comparison of the simulation results with the analytical and the experimental results is presented in the next section. The main advantage of the simulation, in contrast to analytical models, is that the FVC can be estimated at local points for arbitrary strain states of complex curved CoFRP parts. Furthermore, the specific material behavior of UD-NCF, with large shear and superimposed transverse strain, can be captured sufficiently enough by the used macroscopic model, as long as mesoscopic effects, such as roving deformation or out-of-plane undulation, remain small compared to the global deformation.

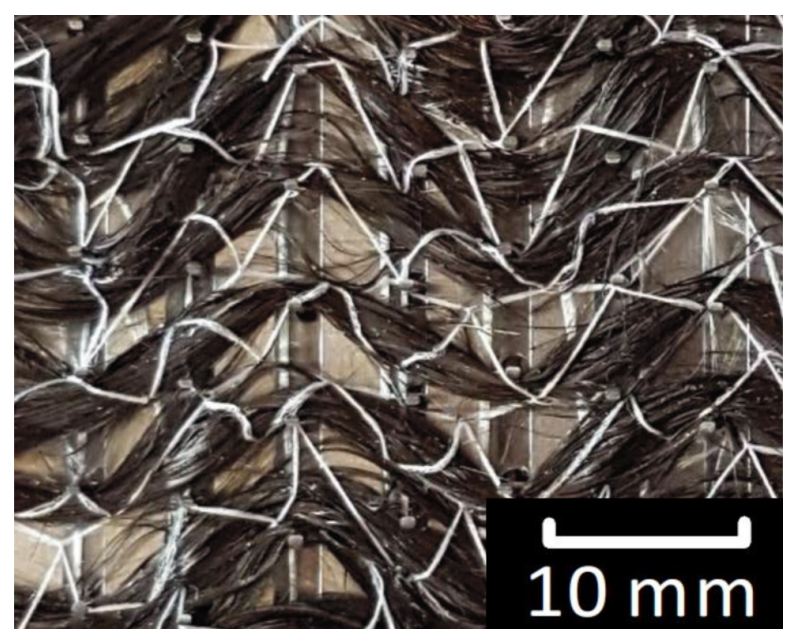

Figure 10. Macro-photography of occurring gaps for wavy samples at an amplitude of $3.5 \mathrm{~mm}$.

\subsection{Experimental Results and Comparison to Simulation Results}

The areal weight of the undeformed NCF was measured to $325 \pm 3 \mathrm{~g} / \mathrm{m}^{2}$ which is very close to the specifications. This areal weight was used to determine the theoretical FVC for the wavy pattern and gapping samples. For the shearing samples, a second roll was used which has a slightly higher areal weight of $338 \pm 3 \mathrm{~g} / \mathrm{m}^{2}$. A summary of the calculated FVC for each batch is given in Table 1 . The areal weight of the different batches varies due to the manufacturing process of the UD-NCF. To achieve the required FVC for the undeformed laminate, the thickness needs to be adjusted. Since the weight of each preform is evaluated, the thickness is the parameter which defines the resulting FVC at different areal weights of the UD-NCF (cf. Table 1).

Determination of standard deviations is not easy for the deformed samples: in general, each fabric sample with a draping effect was manufactured individually and then several samples were weighed together to determine the mean areal weight value over all samples. This procedure is necessary as the area of the deformed zone in the fabric is, due to the fabrication method, very small $(100 \mathrm{~mm} \times 100 \mathrm{~mm}$ for wavy and gapped preforms). Thus, the deformed fabric samples weigh very little and the mass variation of the samples exceeds the sensitivity of the scale. Therefore, the standard deviation for the draping tests was investigated at larger sheared samples. These samples have a size of $200 \mathrm{~mm} \times 200 \mathrm{~mm}$ (cf. Section 4.1). The scatter of five samples for each shear angle are in the range of $0.6 \%$ to $0.9 \%$. 
Table 1. Theoretical laminate thickness dependent on areal weight and fiber volume content for $n_{\mathrm{L}}=6$ plies.

\begin{tabular}{lcc}
\hline & \multicolumn{2}{c}{ Assumed Fiber Volume Content (FVC) of the Laminate } \\
\hline & $\mathbf{4 8 \%}$ & $\mathbf{6 0 \%}$ \\
\hline Areal weight $325 \mathrm{~g} / \mathrm{m}^{2}$ (batch 1) & $2.24 \mathrm{~mm}$ & $1.80 \mathrm{~mm}$ \\
Areal weight $338 \mathrm{~g} / \mathrm{m}^{2}$ (batch 2$)$ & $2.33 \mathrm{~mm}$ & $1.87 \mathrm{~mm}$ \\
\hline
\end{tabular}

\subsubsection{Wavy Pattern}

A comparison of the analytical, experimental and simulation results of the FVC for different fiber waviness is given in Table 2. The experimentally determined FVC was calculated from the resulting areal weight of the preformed samples. CT scans were used to verify the geometrical dimensions of the waves on single samples. Since all measured wavelengths complied with the set wavelengths, a generally good agreement of the wavelengths is assumed. For all evaluated fiber waviness, the FVC increases for increasing $A / \lambda$ ratios. The experimental results show a good correlation with the analytical results for amplitudes $A$ up to $2 \mathrm{~mm}$, corresponding to $A / \lambda$ ratios up to 0.1 . The stitching yarn is primarily responsible for the deformation behavior. If the amplitude exceeds $2 \mathrm{~mm}$, deviations from the target FVC increase, while the areal weight remains constant. The reason for this effect is assumed to be in the tricot loop stitching pattern (cf. Figure 10). The stitching yarn inhibits the free motion of the roving bundles. The roving is subjected to higher tension, if $A / \lambda$ ratio increases, and the waves turning points are not fully formed. The roving takes the shortest path between antipodal displaced needles, which also leads to gapping for amplitudes above $2 \mathrm{~mm}$ for this type of fabric. The maximum $A / \lambda$-ratio that can be reproduced is 0.1 as the evaluation of the CT scans shows: in Figure 11 left, three samples with different amplitudes are shown, and the target amplitude is added as a red curve. For the CT scan, the dry preforms are compressed to the thickness of the cured laminate. With higher amplitude values, the amount of irregularities increases and the gaps are clearly visible for deformations beyond the $A / \lambda=0.1$ threshold. According to CT scans in all plies of the stack, uniform deformation results are obtained. Individual plies are difficult to differentiate, since waves lie directly on top of each other.

During deformation, a spring back effect in the wavy section of $5 \lambda$ was observed for $A / \lambda$ ratios above 0.05 . Therefore, the applied amplitude had to be increased to achieve the specified amplitude. If the total length of the preform has to be increased, e.g., to manufacture tensile specimens (total length of specimen $250 \mathrm{~mm}$ according to DIN EN ISO 527-5), more fibers have to slide through the undeformed area, especially for larger $A / \lambda$ ratios, which increases the friction during forming. To achieve reproducible results for $A / \lambda>0.05$, it is recommended to reduce the wavy section of the preform to $3 \lambda$, if the total length of the preform exceeds $200 \mathrm{~mm}$. The areal weight values given in Table 2 are the average value of five samples weighed together.

The simulation results lead to a very good correlation to the analytical solution, but cannot capture the deformation of the roving above amplitudes of $2 \mathrm{~mm}$ (cf. Figure 10). The slight difference between simulation and analytical results emerge from the zigzag pattern of the mesh (cf. Figure 9 wavy pattern). The deviation equals to the proportion of an arc length of a sinusoidal wave to an arc length of a zigzag path. Although the applied waviness creates alternating homogeneous shear and uniformly perpendicular strain, true material behavior is captured reliably by simulation up to shear strain of $0.38 \mathrm{rad}$ and perpendicular strain of $7 \%$ at $A / \lambda=0.1$. 

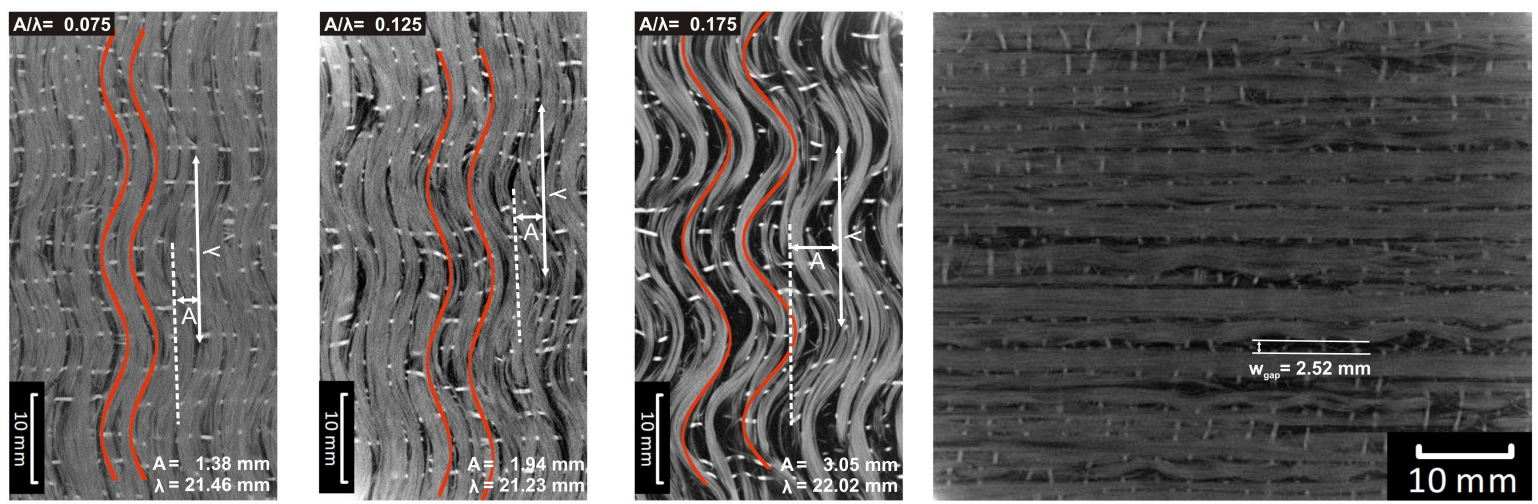

Figure 11. Computer tomography scan of a preform with waves (target values $A / \lambda=$ $0.075,0.125$ and 0.175 ) (left) and gaps with $w_{\text {gap }}=2.5 \mathrm{~mm}$ (right).

Table 2. Comparison of fiber volume content results for wavy preforms with a wave length $\lambda=20 \mathrm{~mm}$, number of plies $n_{\mathrm{L}}=6$ and an assumed laminate thickness of $t=2.24 \mathrm{~mm}$.

\begin{tabular}{|c|c|c|c|c|c|c|}
\hline \multirow[b]{2}{*}{$\begin{array}{c}\text { Amplitude } \\
\text { A/mm }\end{array}$} & \multirow[b]{2}{*}{$\begin{array}{c}A / \lambda \text { Ratio } \\
A / \lambda /-\end{array}$} & \multirow{2}{*}{$\begin{array}{c}\text { Experimental } \\
\text { FVC } \\
\varphi_{\mathrm{f}} / \% \\
\end{array}$} & \multicolumn{2}{|c|}{ Analytical } & \multicolumn{2}{|c|}{ Simulation } \\
\hline & & & $\begin{array}{l}\text { FVC } \\
\varphi_{\mathrm{f}} / \%\end{array}$ & $\begin{array}{c}\text { Deviation } \\
/ \% \\
\end{array}$ & $\begin{array}{l}\text { FVC } \\
\varphi_{\mathrm{f}} / \% \\
\end{array}$ & $\begin{array}{c}\text { Deviation } \\
/ \% \\
\end{array}$ \\
\hline 0.0 & 0.000 & 47.9 & 48.0 & 0.2 & 48.0 & 0.2 \\
\hline 0.5 & 0.025 & 48.2 & 48.3 & 0.3 & 48.2 & 0.2 \\
\hline 1.0 & 0.050 & 49.1 & 49.2 & 0.1 & 49.0 & -0.3 \\
\hline 1.5 & 0.075 & 50.4 & 50.6 & 0.4 & 50.1 & -0.5 \\
\hline 2.0 & 0.100 & 52.0 & 52.4 & 0.9 & 51.7 & -0.6 \\
\hline 2.5 & 0.125 & 52.3 & 54.7 & 4.6 & 53.7 & 2.6 \\
\hline 3.0 & 0.150 & 52.3 & 57.3 & 9.6 & 56.0 & 7.0 \\
\hline 3.5 & 0.175 & 52.3 & 60.2 & 15.3 & 58.6 & 12.1 \\
\hline 4.0 & 0.200 & 52.4 & 63.4 & 20.9 & 61.5 & 17.3 \\
\hline
\end{tabular}

\subsubsection{Fiber Gapping}

When creating gaps, the polyester stitching yarn with its right-left tricot pattern is primarily responsible for the deformation behavior of the fabric. The seams of the stitching yarn run in fiber direction and the upper thread forms the zigzag pattern. Gaps are created by moving the roving bundles perpendicular to their longitudinal direction. Thus, the sharp angle of the zigzag pattern becomes even sharper (see Figure 12). With an increasing gapping distance, the roving bundles become wider-as they are fixed between the seams of the stitching yarn-and are forced into an in-plane waviness due to the sharpening angles of the zigzag pattern. These effects become more visible above $2 \mathrm{~mm}$ gap size as the CT scan in Figure 11 (right) shows, where waves occur due to the deformed stitching yarn.
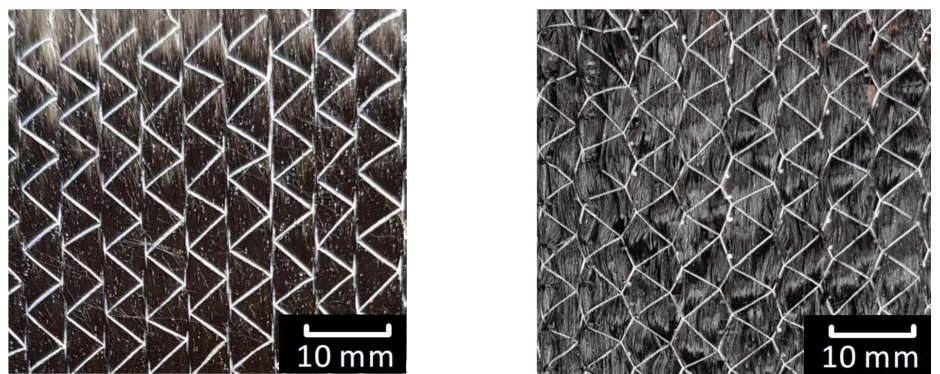

Figure 12. Undeformed fabric (left), fabric with gaps: roving becomes wider and the angle of the stitching yarn becomes sharper (right). 
The analytical, experimental and simulation results for different gap widths are given in Table 3 . Analytical and numerical results show a good correlation with experimental results for small gapping distances and a slight deviation of $3.7 \%$ for larger gaps. Gaps above $w_{\text {gap }}=1.1 \mathrm{~mm}$ lead to in-plane undulation of the fibers, which is an explanation for the higher FVC with increasing gapping distance. The areal weight values given in Table 3 are the average value of five samples weighed together.

The simulation model predicts homogeneous stitching and transverse strain distribution up to $50 \%$ for a gap width of $w_{\text {gap }}=2.5 \mathrm{~mm}$. At such large deformations, nonlinear material behavior needs to be considered to get reliable FVC predictions in composite parts. The occurring fiber waviness for large gaps due to stitching strain (cf. Figure 11 right) is not captured by the simulation model. The FVC predictions from simulation and analytical results are identical here.

Table 3. Comparison of fiber volume content results for gapped preforms with $n_{\mathrm{L}}=3$ (each layer consists of gapped and a fixed layer) and an assumed laminate thickness of $t=1.87 \mathrm{~mm}$.

\begin{tabular}{cccccc}
\hline & Experimental & \multicolumn{2}{c}{ Analytical } & \multicolumn{2}{c}{ Simulation } \\
\hline Gap Size & FVC & FVC & Deviation & FVC & Deviation \\
$\boldsymbol{w}_{\text {gap }} / \mathbf{m m}$ & $\boldsymbol{\varphi}_{\mathrm{f}} / \%$ & $\boldsymbol{\varphi}_{\mathrm{f}} / \%$ & $/ \%$ & $\boldsymbol{\varphi}_{\mathrm{f}} / \%$ & $/ \%$ \\
\hline 0.0 & 59.7 & 60.0 & 0.6 & 60.0 & 0.6 \\
1.1 & 54.5 & 54.6 & 0.2 & 54.6 & 0.2 \\
2.5 & 51.9 & 50.0 & -3.7 & 50.0 & -3.7 \\
\hline
\end{tabular}

\subsubsection{Fiber Shearing}

When shearing the fabric, the zigzag pattern of the stitching yarn is distorted in a way that one yarn is stretched and the other yarn is compressed. This behavior does not prevent the fiber shearing. For small shearing angles, the fibers run parallel and the fiber alignment is not altered. However, for larger shear angles, the stitching yarn forces the rovings into an out-of-plane undulation (Figure 13). This irregular out-of-plane waviness can explain the higher areal weight for $\alpha=35.5^{\circ}$ samples in experiments, since the arc length of the fibers is longer in comparison to straight fibers and thus more fibers are clustered. The resulting mean FVC and the corresponding standard deviation for each shear angle is given in Table 4. In comparison to the deformation modes waviness and fiber gapping, the stitching yarn has a smaller influence on the fiber shearing behavior of the fabric.
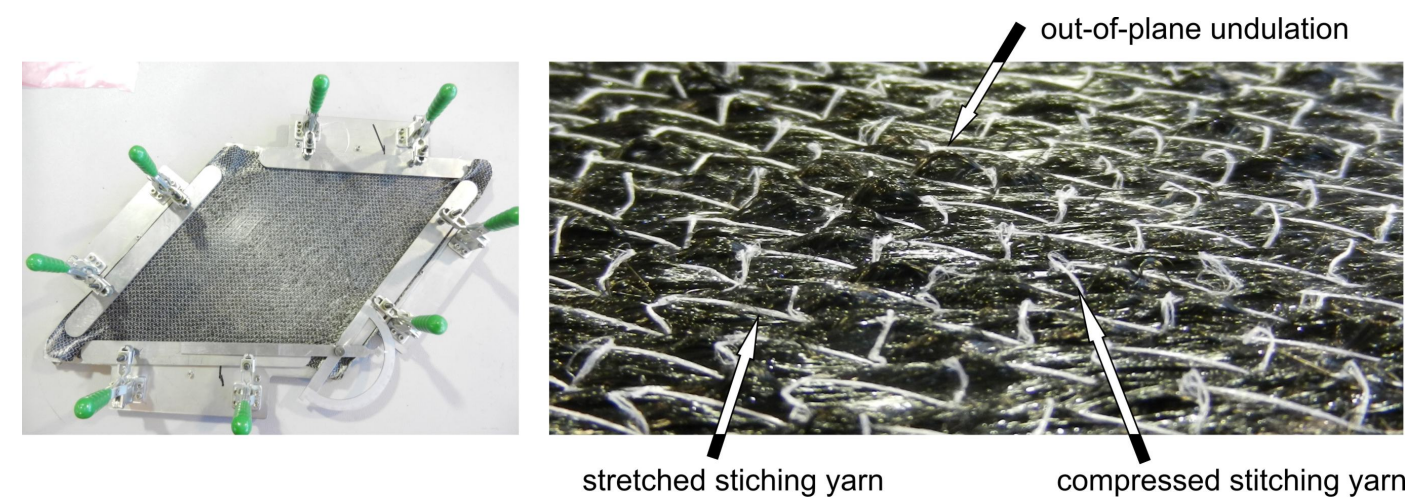

Figure 13. Shear frame with sheared UD-NCF at $\alpha=35.5^{\circ}$ (left) and deformation of the stitching yarn with out-of-plane fiber undulation (right).

The macroscopic material model used for simulation defines the membrane behavior only and cannot capture out-of-plane undulations. Nevertheless, by utilizing the perpendicular strain to the fiber direction, the roving compression can be fully captured and the FVC equals the analytical results. Although the occurring shear and transverse strains at $\alpha=35.5^{\circ}$ are much higher than for a wavy pattern at $A / \lambda=0.1$ (cf. Section 5.2.1) due to uniform strain distribution, the overall prediction of the FVC is still very good. In conclusion, as long as mesoscopic effects, such as out-of-plane undulations 
or roving deformation within the tricot loop stitching, are small, the prediction of the macroscopic draping model provides reliable FVC results.

Table 4. Comparison of fiber volume content results for sheared preforms with $n_{\mathrm{L}}=6$ and an assumed laminate thickness of $t=2.33 \mathrm{~mm}$.

\begin{tabular}{|c|c|c|c|c|c|}
\hline \multirow[b]{2}{*}{$\begin{array}{c}\text { Shear Angle } \\
\alpha /^{\circ}\end{array}$} & \multirow{2}{*}{$\begin{array}{c}\text { Experimental } \\
\text { FVC } \\
\varphi_{\mathrm{f}} / \% \\
\end{array}$} & \multicolumn{2}{|c|}{ Analytical } & \multicolumn{2}{|c|}{ Simulation } \\
\hline & & $\begin{array}{l}\text { FVC } \\
\varphi_{\mathrm{f}} / \%\end{array}$ & $\begin{array}{c}\text { Deviation } \\
/ \% \\
\end{array}$ & $\begin{array}{l}\text { FVC } \\
\varphi_{\mathrm{f}} / \%\end{array}$ & $\begin{array}{c}\text { Deviation } \\
/ \%\end{array}$ \\
\hline 0.0 & $48.1 \pm 0.0$ & 48.0 & -0.2 & 48.0 & -0.2 \\
\hline 25.0 & $53.3 \pm 0.4$ & 53.0 & -0.7 & 53.0 & -0.7 \\
\hline 35.5 & $61.2 \pm 0.6$ & 59.0 & -3.7 & 59.0 & -3.7 \\
\hline
\end{tabular}

\section{Interdependency of the Fiber Volume Content at Arbitrary Strain States}

As mentioned above, the uniformly distributed strains for load cases like fiber gapping, shearing or waviness lead to a homogeneous distribution of the FVC. However, as the experimental results have shown, the draping effects occur in combination with each other. Preforms with waviness create gapping for higher $A / \lambda$ ratios (cf. Figures 10 and 11). Gapping and shearing induce undulations for higher deformations. Such cases lead to a change of the local FVC. In this section, the interdependency of the draping effects is discussed based on the deformation and therefore on strain components.

For arbitrary strain states, the strain components have an interdependency that results from the used strain measures. The non-orthogonal membrane strain $\varepsilon_{2}$ (Equation (2)) and the shear strain $\gamma_{12}$ (Equation (3)) can be rewritten to

$$
1+\varepsilon_{2}=\sqrt{F_{12}^{2}+F_{22}^{2}} \quad \text { and } \quad \psi_{12}=\frac{\pi}{2}-\gamma_{12}
$$

If both equations are inserted into the formulation of the perpendicular strain $\varepsilon_{\perp}$ (Equation (4)), the interrelation between the strain components $\varepsilon_{2}, \gamma_{12}$ and $\varepsilon_{\perp}$ becomes obvious:

$$
\frac{1+\varepsilon_{\perp}}{1+\varepsilon_{2}}=\cos \left(\gamma_{12}\right) \text {. }
$$

For arbitrary shear strain and physically plausible deformations, the right-hand side of Equation (28) remains always positive, $\cos \left(\gamma_{12}\right) \geq 0$. Therefore, the strain components $\varepsilon_{2}$ and $\varepsilon_{\perp}$ must have the same algebraic sign and $\varepsilon_{\perp}$ is smaller than $\varepsilon_{2}$. Only in cases where $\varepsilon_{2}$ or $\varepsilon_{\perp}$ are equal to zero, the algebraic sign may change

$$
\begin{array}{r}
\varepsilon_{2}=0: \quad 1+\varepsilon_{\perp}=\cos \left(\gamma_{12}\right) \rightarrow \varepsilon_{\perp} \leq 0 \quad \text { or } \\
\varepsilon_{\perp}=0: \quad \frac{1}{1+\varepsilon_{2}}=\cos \left(\gamma_{12}\right) \rightarrow \varepsilon_{2} \geq 0 .
\end{array}
$$

The manufactured draping effects create strain states, where either $\varepsilon_{2}$ or $\gamma_{12}$ is unequal to zero. The perpendicular strain $\varepsilon_{\perp}$ is unequal to zero for all evaluated load cases in Section 5. If waviness (causes simple shear load, cf. Figure 14b) or shearing (causes pure shear load cf. Figure 14c) is applied to the fabric, the stitching strain $\varepsilon_{2}$ equals zero and the shear strain $\gamma_{12}$ is directly connected to the perpendicular strain $\varepsilon_{\perp}$. For gapping, the shear strain $\gamma_{12}$ equals zero and the stitching strain $\varepsilon_{2}$ is proportional to $\varepsilon_{\perp}$. In the case of simultaneously occurring draping effects, the FVC will only change, if the perpendicular strain deviates from zero. Two cases are possible which result in $\varepsilon_{\perp}=0$ and thus in no change of the FVC: a simple shear load case acting in fiber direction (see Figure 14a) or a simple shear load case in stitching direction (e.g., waviness Figure 8a) together with stitching strain. Stitching strain $\varepsilon_{2} \geq 0$, which causes gapping, always occurs in conjunction with positive perpendicular strain $\varepsilon_{\perp}$. Therefore, the perpendicular strain is a strong indicator for changes in FVC. 
Besides the discussed strains, the strain in fiber direction may change the FVC for values $\varepsilon_{1} \leq 0$. This case especially occurs in corner areas, where the rovings are compressed from both directions of the corner. For the case $\varepsilon_{\perp}=0$ and $\varepsilon_{1}<0$, the FVC would increase. In conclusion, for unconstrained draping simulations, it is recommended to use the complete deformation gradient (Equation (24)) to capture the change of the element area (including strain in fiber direction) and therefore the change of the FVC.

(a)

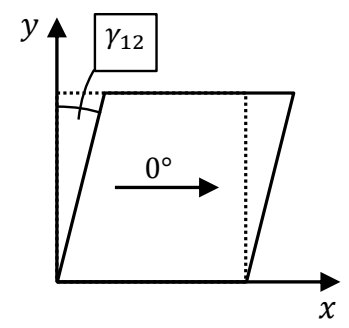

(b)

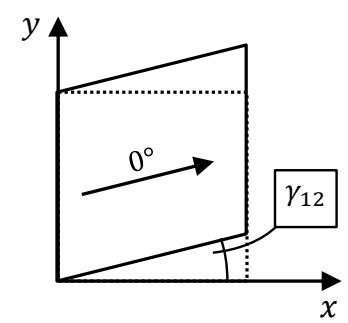

(c)

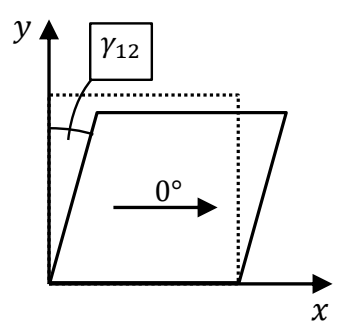

Figure 14. Simple shear load cases (a) and (b) and pure shear load case (c) resulting in the same shear strain $\gamma_{12}$, but different $\varepsilon_{1}, \varepsilon_{2}$ and $\varepsilon_{\perp}$.

\section{Conclusions}

For complex geometries, forming of composite parts leads to changes in fiber direction and fiber volume content (FVC). The prediction of the local fiber orientation from draping simulation (e.g., finite element or kinematic simulation) has been widely evaluated. In the present work, the change of the FVC of unidirectional non-crimp fabrics (UD-NCF) textiles due to draping of composite parts is presented. Three deformation types of the textile, so-called draping effects (waviness, gapping and transverse compression due to shearing), are identified as the main reasons for a change of the local FVC.

Different experimental sliding mechanisms were used to impose wavy pattern, gapped or sheared preforms with repeatable draping effects that cause a constant fiber volume change. The limitations of the fabric deformation were determined. The stitching yarn strongly influences the deformation behavior of the UD-NCF and causes additional undulation of the rovings besides the target draping effects. For each draping effect, simple analytical solutions of the resulting FVC are introduced. Based on the local fabric weight per unit area of each preform, the FVC for a specific laminate thickness or cavity height is determined experimentally. To determine the resulting FVC from draping simulation, a previously developed macroscopic material model was used. The results show a very good correlation between the analytical solution, the experimental results and the numerical solution. The FVC changes between 5\% to 13\% compared to the initial state and depending on the draping effect. For simple deformations such as gapping or shearing, which create uniformly distributed draping effects and also very large strains $\left(\varepsilon_{2}=50 \%\right.$ and $\left.\gamma_{12}=0.62 \mathrm{rad}\right)$, the FVC can be estimated reliably by analytical or numerical results and no experimental tests are needed. For more complex deformations, such as waviness, the deviations between the analytical or numerical prediction and the experimental results become larger above an amplitude to wavelength ratio of $A / \lambda=0.1$. The reason for the deviation results from the non-homogeneous and punctual deformation of the wavy fabric, which cannot be captured by the analytical or numerical model.

Due to deformation of the fabric, each draping effect leads to interdependencies of the strain components. For large deformations of the fabric, these interdependencies cause a superposition of draping effects. It could be shown that the strain component perpendicular to fiber direction has a significant influence on the local FVC. Besides the local fiber orientation, the applied draping simulation model provides a reliable prediction of the local FVC. In conjunction with a continuous virtual process chain, the information of the local fiber orientation and the local FVC can be transferred to structural simulation. This workflow allows for predicting a more reliable structural behavior. 
Further experimental tests on infiltrated specimens with uniformly and non-uniformly distributed draping effects will enable validation of the capabilities of the continuous virtual process chain to predict the structural performance under consideration of draping effects.

Author Contributions: S.G. contributed to the numerical simulations, investigation and writing of the original draft; E.K. contributed to the experimental results and writing of the original draft; L.K. and R.B. contributed to the scientific interpretation of the data and were responsible for supervision, and coordination of the project (L.K. numerics, R.B. experimental). L.K. and M.G. contributed to funding acquisition.

Funding: This work was performed within the research project "Experimental and virtual analysis of draping effects and their impact on the mechanical behavior of composite components" (KA4224/1-1, GU614/11-1) funded by the Deutsche Forschungsgemeinschaft (DFG). Additionally, the work is part of the research of the Young Investigator Group (YIG) "Tailored Composite Materials for Lightweight Vehicles" at KIT FAST, funded by the Vector Stiftung.

Acknowledgments: We would like to thank the DFG and the Vector Stiftung for the financial support, which enabled the detailed study of the draping effects.

Conflicts of Interest: The authors declare no conflict of interest.

\section{References}

1. Hufenbach, W.; Böhm, R.; Gude, M.; Berthel, M.; Hornig, A.; Ručevskis, S.; Andrich, M. A test device for damage characterisation of composites based on in situ computed tomography. Compos. Sci. Technol. 2012, 72, 1361-1367. [CrossRef]

2. Böhm, R.; Stiller, J.; Behnisch, T.; Zscheyge, M.; Protz, R.; Radloff, S.; Gude, M.; Hufenbach, W. A quantitative comparison of the capabilities of in situ computed tomography and conventional computed tomography for damage analysis of composites. Compos. Sci. Technol. 2015, 110, 62-68. [CrossRef]

3. Kärger, L.; Bernath, A.; Fritz, F.; Galkin, S.; Magagnato, D.; Oeckerath, A.; Schön, A.; Henning, F. Development and validation of a CAE chain for unidirectional fibre reinforced composite components. Compos. Struct. 2015, 132, 350-358. [CrossRef]

4. Mayer, N.; Prowe, J.; Havar, T.; Hinterhölzl, R.; Drechsler, K. Structural analysis of composite components considering manufacturing effect. Compos. Struct. 2016, 140, 776-782. [CrossRef]

5. Kärger, L.; Galkin, S.; Zimmerling, C.; Dörr, D.; Linden, J.; Oeckerath, A.; Wolf, K. Forming optimisation embedded in a CAE chain to assess and enhance the structural performance of composite components. Compos. Struct. 2018, 192, 143-152. [CrossRef]

6. Brunbauer, J.; Stadler, H.; Pinter, G. Mechanical properties, fatigue damage and microstructure of carbon/epoxy laminates depending on fibre volume content. Int. J. Fatigue 2015, 70, 85-92. [CrossRef]

7. Brunbauer, J.; Pinter, G. Effects of mean stress and fibre volume content on the fatigue-induced damage mechanisms in CFRP. Int. J. Fatigue 2015, 75, 28-38. [CrossRef]

8. Huang, Z.M. A bridging model prediction of the ultimate strength of composite laminates subjected to biaxial loads. Compos. Sci. Technol. 2004, 64, 395-448. [CrossRef]

9. Bleier, A. Prüfverfahren zur Ermittlung exakter Werkstoffkennwerte einer unidirektionalen Schicht unter Besonderer Berücksichtigung Physikalischer Nichtlinearitäten. Ph.D. Thesis, RWTH Aachen University, Aachen, Germany, 2011.

10. Garnich, M.R.; Karami, G. Finite Element Micromechanics for Stiffness and Strength of Wavy Fiber Composites. J. Compos. Mater. 2004, 38, 273-292. [CrossRef]

11. Karami, G.; Garnich, M. Effective moduli and failure considerations for composites with periodic fiber waviness. Compos. Struct. 2005, 67, 461-475. [CrossRef]

12. Karami, G.; Garnich, M. Micromechanical study of thermoelastic behavior of composites with periodic fiber waviness. Compos. Part B Eng. 2005, 36, 241-248. [CrossRef]

13. Hufenbach, W.; Böhm, R.; Thieme, M.; Winkler, A.; Mäder, E.; Rausch, J.; Schade, M. Polypropylene/glass fibre 3D-textile reinforced composites for automotive applications. Mater. Des. 2011, 32, 1468-1476. [CrossRef]

14. Maron, B.; Garthaus, C.; Hornig, A.; Lenz, F.; Hübner, M.; Gude, M. Forming of carbon fiber reinforced thermoplastic composite tubes-Experimental and numerical approaches. CIRP J. Manuf. Sci. Technol. 2017, 18, 60-64. [CrossRef] 
15. Hufenbach, W.; Hornig, A.; Gude, M.; Böhm, R.; Zahneisen, F. Influence of interface waviness on delamination characteristics and correlation of through-thickness tensile failure with mode I energy release rates in carbon fibre textile composites. Mater. Des. 2013, 50, 839-845. [CrossRef]

16. Altmann, A.; Taubert, R.; Mandel, U.; Hinterhoelzl, R.; Drechsler, K. A continuum damage model to predict the influence of ply waviness on stiffness and strength in ultra-thick unidirectional Fiber-reinforced Plastics. J. Compos. Mater. 2015, 50, 2739-2755. [CrossRef]

17. Hsiao, H.M.; Daniel, I.M. Elastic properties of composites with fiber waviness. Compos. Part A Appl. Sci. Manuf. 1996, 27, 931-941. [CrossRef]

18. Hsiao, H.M.; Daniel, I.M. Effect of fiber waviness on stiffness and strength reduction of unidirectional composites under compressive loading. Compos. Sci. Technol. 1996, 56, 581-593. [CrossRef]

19. Wang, B.; Uda, N.; Ono, K.; Nagai, H. Effect of micro in-plane fiber waviness on compressive properties of unidirectional fabric composites. J. Compos. Mater. 2018, 52, 2065-2074. [CrossRef]

20. Takeda, T. Micromechanics Model for Three-dimensional Effective Elastic Properties of Composite Laminates with Ply Wrinkles. Compos. Struct. 2018, 189, 419-427. [CrossRef]

21. Rudd, C.D.; Middleton, V.; Owen, M.J.; Long, A.C.; McGeehin, P.; Bulmer, L.J. Modelling the processing and performance of preforms for liquid moulding processes. Compos. Manuf. 1994, 5, 177-186. [CrossRef]

22. McBride, T.M.; Chen, J. Unit-cell geometry in plain-weave fabrics during shear deformations. Compos. Sci. Technol. 1997, 57, 345-351. [CrossRef]

23. Mohammed, U.; Lekakou, C.; Bader, M.G. Experimental studies and analysis of the draping of woven fabrics. Compos. Part A Appl. Sci. Manuf. 2000, 31, 1409-1420. [CrossRef]

24. Heardman, E.; Lekakou, C.; Bader, M. In-plane permeability of sheared fabrics. Compos. Part A Appl. Sci. Manuf. 2001, 32, 933-940. [CrossRef]

25. Louis, M.; Huber, U. Investigation of shearing effects on the permeability of woven fabrics and implementation into LCM simulation. Compos. Sci. Technol. 2003, 63, 2081-2088. [CrossRef]

26. Demaría, C.; Ruiz, E.; Trochu, F. In-plane anisotropic permeability characterization of deformed woven fabrics by unidirectional injection. Part I: Experimental results. Polym. Compos. 2007, 28, 797-811.

27. Boisse, P.; Hamila, N.; Madeo, A. The difficulties in modeling the mechanical behavior of textile composite reinforcements with standard continuum mechanics of Cauchy. Some possible remedies. Int. J. Solids Struct. 2018, 154, 55-65. [CrossRef]

28. Schirmaier, F.J;; Dörr, D.; Henning, F.; Kärger, L. A macroscopic approach to simulate the forming behaviour of stitched unidirectional non-crimp fabrics (UD-NCF). Compos. Part A Appl. Sci. Manuf. 2017, 102, 322-335.

29. Dörr, D.; Schirmaier, F.J.; Henning, F.; Kärger, L. A viscoelastic approach for modeling bending behavior in finite element forming simulation of continuously fiber reinforced composites. Compos. Part A Appl. Sci. Manuf. 2017, 94, 113-123. [CrossRef]

30. Schirmaier, F. Experimentelle Untersuchung und Simulation des Umformverhaltens nähgewirkter unidirektionaler Kohlenstofffasergelege. Ph.D. Thesis, Institut für Fahrzeugsystemtechnik (FAST), Karlsruhe, Germany, 2017.

31. Cherif, C. Textile Materials for Lightweight Constructions; Springer: Berlin/Heidelberg, Germany, 2016.

32. Hsiao, H.M.; Wooh, S.C.; Daniel, I.U. Fabrication methods for unidirectional and crossply composites with fiber waviness. J. Adv. Mater. 1995, 26, 19-26.

33. Brökel, J. Untersuchungen zum Einfluss gezielt Nicht Geradlinig Eingebrachter Faserverstärkungen auf die Mechanischen Eigenschaften einer Nachgiebigen Polymermatrix. Ph.D. Thesis, Lehrstuhl für Konstruktionstechnik und Leichtbau, Rostock, Germany, 2008.

34. Davidson, P.; Waas, A.; Yerramalli, C.S.; Chandraseker, K.; Faidi, W. Effect of fiber waviness on the compressive strength of unidirectional carbon composites. In Proceedings of the 53rd AIAA/ASME/ ASCE/AHS/ASC Structures, Structural Dynamics and Materials Conference 20th AIAA/ASME/AHS Adaptive Structures Conference 14th AIAA, Honolulu, HI, USA, 23-26 April 2012; p. 1422.

35. Schirmaier, F.J.; Weidenmann, K.A.; Kärger, L.; Henning, F. Characterisation of the draping behaviour of unidirectional non-crimp fabrics (UD-NCF). Compos. Part A Appl. Sci. Manuf. 2016, 80, 28-38. [CrossRef]

(C) 2019 by the authors. Licensee MDPI, Basel, Switzerland. This article is an open access article distributed under the terms and conditions of the Creative Commons Attribution (CC BY) license (http:/ / creativecommons.org/licenses/by/4.0/). 